\title{
EDUCAÇÃO AMBIENTAL E INTERDISCIPLINARIDADE: A IMPORTÂNCIA DA ÁGUA NA VIDA DOS RIBEIRINHOS DA ILHA DAS ONÇAS (FURO CONCEIÇÃO), BARCARENA, PARÁ, BRASIL
}

\section{ENVIRONMENTAL EDUCATION INTERDISCIPLINARITY: THE IMPORTANCE OF WATER IN THE LIFE OF THE RIVERINES OF THE ISLAND OF THE ILHAS DAS ONÇAS (FURO CONCEIÇÃO), BARCARENA, PARÁ, BRAZIL}

\author{
Fabrício César da Costa Rodrigues ${ }^{1}$ \\ Rogério Tadeu Mendes Palheta ${ }^{2}$
}

\section{RESUMO}

Este artigo enfoca a Educação Ambiental Interdisciplinar como um dos instrumentos indispensáveis para compreensão das relações entre as comunidades ribeirinhas paraenses e a natureza, no seu exercício da cidadania, tendo como objetivo discutir como os ribeirinhos da Comunidade do Furo Conceição, localizada na Ilha das Onças, Barcarena, Pará representam as suas relações sociais com os recursos hídricos e seus impactos, considerando a escola local como propulsora de iniciativa de práticas pedagógicas curriculares sustentáveis. Assim, desenvolveu-se um projeto de sensibilização da comunidade para uma postura de responsabilidade socioambiental, incluindo alunos do $1^{\circ}$ ao $4^{\circ}$ ano do Ensino Fundamental de classe multisseriada. Nesse contexto, buscou-se como base metodológica o estudo de caso, compreendendo a realidade em profundidade (social, econômico e ambiental) da comunidade do Furo Conceição.

Palavras-chave: Educação Ambiental. Interdisciplinaridade. Sustentabilidade. Ribeirinhos.

\footnotetext{
ABSTRACT

This article focuses on Interdisciplinary Environmental Education as one of the indispensable tools for understanding the relationships between the riverside communities of Pará and nature, in their exercise of citizenship, with the objective of discussing how the riverside communities as: Furo, Onças, Barcarena, Pará represent their social relations with water resources and their impacts, considering the local school as a propeller of the initiative of sustainable curricular pedagogical practices. Thus, a community awareness project was developed for a socio-environmental responsibility posture, including students from the 1st to the 4th year of elementary school in the multi-grade class. In this context, we sought as a methodological basis the case study, comprising the reality in depth (social, economic and environmental) of the Furo Conceição community.

Keywords: Environmental Education. Interdisciplinarity. Sustainability. Riverines.

${ }^{1}$ Mestrado em Gestão de Recursos Naturais e Desenvolvimento Local na AmazôniaNUMA/PPGEDAM/UFPA (2016). Atualmente coordena um grupo de pesquisa multidisciplinar de educação ambiental e tecnologia social de abastecimento de água pluvial na llha das Onças (Barcarena -Pará).

${ }^{2}$ Graduado em engenharia Civil pela Universidade Federal do Pará-UFPA.
} 


\section{INTRODUÇÃO}

O referido trabalho traz para debate a concepção de Educação Ambiental, buscando situar a importância da água como recurso natural indispensável à vida de populações ribeirinhas na Amazônia, o que adquire uma dimensão de extrema relevância para o entendimento dessa questão no cotidiano dessas comunidades. Dessa forma, o projeto aqui apresentado é feito em parceria com os moradores de comunidades ribeirinhas da llha das Onças no município de Barcarena, Pará (Furo Conceição) e alunos da Universidade Federal do Pará (UFPA).

Seu objetivo foi o de compreender o modo como os ribeirinhos representam as suas relações sociais com os recursos hídricos no contexto do seu modo de vida levando em consideração também a comunidade escolar da Ilha e como essas representações são dificultosas em sua vida cotidiana.

A atividade a ser desenvolvida se iniciou com a formação de uma equipe acadêmica interdisciplinar, pesquisando sobre a importância da água para os ribeirinhos e propondo alternativas sobre o abastecimento da água potável para atender às demandas nessas comunidades. No desenvolvimento da pesquisa buscou-se os conceitos, os paradigmas e relações de sustentabilidade ambiental com a água para esses moradores. Nesse sentido, Sachs (1980, p. 7) afirma que "trata-se de buscar soluções locais aos problemas globais, valorizando do melhor modo possível as potencialidades de cada ecossistema, os recursos específicos do mesmo e as contribuições de cada cultura".

Verificou-se na pesquisa que a população ribeirinha da Ilha das Onças se encontra às margens das políticas públicas, de saneamento básico e assistência social e em decorrência das condições socioeconômicas vivenciadas, muitas pessoas, principalmente, os jovens, abandonaram a comunidade, pela falta de condições de trabalho e sobrevivência, deslocandose para o ambiente urbano, seja em Icoaraci ou Belém.

Os usos das águas estão presentes de várias formas na vida ribeirinha, reforçando-a pela sensação de pertencimento a esse recurso natural indispensável a sua sobrevivência, o rio é tido como extensão de suas casas: 
"Nas sociedades tradicionais, a água, incluindo rios e lagos, faz parte de um território e um modo de vida, e é base de identidades específicas" (DIEGUES, 2009, p. 4).

Considerando o meio ambiente das ilhas paraenses, existe na legislação educacional brasileira, segundo o que foi preconizado nos Parâmetros Curriculares Nacional (PCN), que estes podem ser inseridos nos temas transversais, bem como nas questões relacionadas à educação ambiental, para que sejam trabalhadas de forma interdisciplinar e contextualizada, sobretudo discutindo e sensibilizando as várias questões e problemáticas sócio ambientais no contexto amazônico.

Os ribeirinhos são identificados pelo seu modo de vida em relação ao uso doméstico da água, o que inclui beber, cozinhar, fazer higiene pessoal, lavar roupas, entre outras utilidades, em geral, com as águas dos rios ou poços, que são armazenadas de diversas formas: em reservatórios, tanques ou filtros de barro e são utilizadas para consumo doméstico no cotidiano.

\section{DESAFIOS PARA AS POLÍTICAS PÚBLICAS no município de Barcarena- Pará e os impactos ambientais nos recursos hídricos}

A gestão pública na região amazônica, considerando os cenários político institucionais, são apontadas como determinantes para na superação das crises de âmbito local e regional. Todavia, recomenda-se que "cada vez mais as intervenções públicas devem ser realizadas com a colaboração das diversas instâncias e com diferentes autoridades hierarquizadas das administrações" (VIDAL; ROSA FILHO, 2011, p.179).

O Brasil dispõe de uma legislação avançada no que diz respeito ao recurso água. Inspirada no modelo francês, a Política Nacional de Recursos Hídricos (PNRH) dispõem de modernos parâmetros de gestão. A partir dessa perspectiva, a PNRH também dispõe de instrumentos considerados necessários para garantir a boa gestão dos usos da água. O Plano Nacional de Recursos Hídricos consolida todos os planos diretores de recursos hídricos de cada bacia hidrográfica, sendo sua elaboração de responsabilidade da Secretaria de Recursos Hídricos (SRH), do Ministério do Meio Ambiente. 
Uma eficiente política de gestão dos recursos hídricos envolve o manejo integrado desses recursos, com previsão de avaliação e proteção da qualidade da água e dos ecossistemas aquáticos (REBOLSAS, 2011). Essas questões ficam amparadas com a Lei Federal no 9984/00, cria a Agência Nacional das Águas (ANA). A ANA tem como inspiração colocar em prática as políticas públicas na área dos recursos hídricos e monitorá-los, além de fazer a cobrança pelo uso da água de uma determinada bacia (RIBEIRO, 2004).

Tais problemáticas requerem questionar outros aspectos que diz respeito ao abastecimento de água potável, ao saneamento e a sustentabilidade rural que não existem nas localidades da llha das Onças, no município de Barcarena no estado do Pará. Entende-se que a gestão municipal de Barcarena adquire um papel determinante para o desenvolvimento do município e, em consequência, da região, ao focar a gestão financeira, de capital e infraestrutura, de pessoas e de tecnologias para a qualificação de tal gestão.

A partir dessa lógica, tanto em Barcarena como em outros municípios paraenses ainda predomina uma gestão burocrática, sem uma racionalidade orientada para alcançar à eficiência somada às pendências e à qualificação na formação dos recursos humanos disponíveis. Tudo isso contribui para obstáculos para o desenvolvimento econômico.

Apesar dos avanços na implantação da Política Estadual de Recursos Hídricos, como a execução de outorgas, criação do sistema de informação de recursos hídricos e dentre outros avanços, ainda tem-se municípios limitados no acesso a essas ferramentas.

De acordo com os dados da Pesquisa Nacional por Amostra de Domicílios, (PNAD), realizada em 2012, cerca de 68,8\% dos domicílios nas áreas rurais não tem acesso à água por meio de uma rede geral de abastecimento. A população capta água de chafarizes e poços protegidos ou não, diretamente de cursos de água sem nenhum tratamento ou de outras fontes alternativas geralmente inadequadas para consumo humano.

Tendo em vista o histórico dos impactos ambientais que incidem na qualidade/potabilidade da água para os moradores ribeirinhos de Barcarena, estes estão relacionadas às questões entre as comunidades e os recursos naturais. E quanto à água? Constatou-se que esse recurso, além da falta de 
saneamento básico e de abastecimento, existe a poluição por agentes químicos contaminando os igarapés e os rios como fonte de suprimento, portanto estes são vistos como inadequados ao uso doméstico.

Entende-se que esse processo, ao longo dos anos em Barcarena, gerou o deslocamento de parte da sua população para áreas periféricas, bem como alterações nos seus aspectos socioambientais, o que provocou fortes mudanças nas condições de vida das populações locais e que proporcionou a população a enfrentar um processo de adaptação a uma outra realidade totalmente diferente (SILVA; MONTEIRO, 2007).

Em decorrência desses empreendimentos industriais temos os danos ambientais que estes causam na exploração e transformação mineral geram ao meio ambiente, ao liberarem seus dejetos (líquidos e sólidos) na natureza por meios diversos como: acidentes ambientais, rede de esgoto, vazamento ou transbordamento de depósitos de resíduos sólidos, vazamento de minerodutos, descarte clandestino de seus efluentes, etc. (BORDALO; SILVA; SANTOS, 2012). A inexistência de Estações de Tratamento de Água (ETA) ou de Estações de Tratamento de Efluentes (ETE) também compromete a qualidade dos corpos hídricos no Pará prejudicando a população local ribeirinha em seu entorno.

Barcarena também presenciou fatos graves de acidentes ambientais, dentre eles, pode-se destacar alguns incidentes ocasionados a partir de algumas ações industriais: A chuva de fuligem que ocorreu no dia 23 de novembro de 2003 e se constituiu numa nuvem negra de fuligem e fumaça que pairou sobre a Vila do Conde. Outro impacto, foi o vazamento de caulim ocasionado pelas atividades da Imerys Rio Capim Caulim, ocorrido no dia 13 de junho de 2007, que provocou a contaminação dos igarapés Curuperé e Dendê, afluentes do rio Pará, decorrendo o remanejamento de 43 famílias. Foram comprometidas as atividades de pesca e banho nestes igarapés, temerosos de que fossem contaminados e/ou viessem adoecer.

O caso mais recente e amplamente divulgado pela mídia, foi a catástrofe ambiental a qual ocorreu em fevereiro de 2018, resultando uma amplitude de graves danos e riscos socioambientais, com o escoamento de efluentes (lama vermelha) a partir de suposto transbordamento de bacias de disposição de rejeitos do processo de beneficiamento de bauxita da Empresa Alunorte 
Alumina do Norte do Brasil S. A. (Hidro Alunorte) localizadas o município de Barcarena/Pa, devido às fortes chuvas ocorridas nos dias 16 e 17 daquele mês.

Vale ressaltar que cabe prostrar-se diante de uma tragédia anunciada, decorrente de tamanha irresponsabilidade do poder público fiscalizador/licenciador e da empresa responsável pelo empreendimento. Ressalte-se que o órgão ambiental estadual é conivente com tal situação, eis que, mesmo perante todas as circunstâncias constatadas, entendeu que não havia elementos para cobrar da empresa a efetivação de um Plano de Emergências, muito embora estes sejam impostos pela Lei de Segurança de Barragens (PARÁ MPPA, 2018).

\begin{abstract}
Destaca-se, ainda, que a população foi surpreendida pelos eventos de despejos de resíduos contaminados no meio ambiente, tendo em vista a inexistência de qualquer comunicação prévia. Evidenciou-se, ademais, o despreparo para enfrentamento de situações de risco à vida, à integridade física das pessoas, bem como ao meio ambiente (INQUÉRITO CIVIL - IC Nº01/2018-MP (SIMP N000654-710/2018) MPPA, 2018, p. 44)
\end{abstract}

A saúde esta diretamente relacionada à qualidade da água, sendo indicador de qualidade de vida. Devido à dificuldade de acesso a água potável na Amazônia, a precariedade no serviço de abastecimento atinge o município de Barcarena, bem como a Ilha das Onças, onde residem várias comunidades ribeirinhas que tem seus rios poluídos e compromete a qualidade desse recurso. A escassez de água, em uma região abundante em água doce, é resultado da negligência de políticas públicas e de uma eficiente gestão para resolver tais problemáticas.

Enfim, pelo exposto acima, emerge o debate crítico de se repensar o contexto institucional e organizacional municipal de Barcarena, que deve dar respostas às demandas atuais como também deve dar prioridade ao desenvolvimento do município e da região. Isso pressupõe também, uma série de mudanças do nível operativo institucional, com o objetivo de fortalecer e racionalizar de forma eficiente as políticas públicas. 


\section{CARACTERIZAÇÃO DA ÁREA DE ESTUDO}

Esta pesquisa foi realizada na Ilha das Onças, especificamente, na comunidade do Furo Conceição, localizada no município paraense de Barcarena (Mapa 1), em que proximidade com o município de Belém mantém uma significativa interação e influência do meio urbano no modo de vida ribeirinho, sobretudo entre os mais jovens na expectativa por melhores condições de trabalho e ascensão social.

São cerca de 820 famílias que habitam a Ilha das Onças e que convivem com a problemática da elevada contaminação destas águas por coliformes totais segundo os padrões bacteriológicos de potabilidade estabelecido pela legislação brasileira (BRASIL. Portaria MS n. 2.914, de 12 de dezembro de 2011).

Entende-se que as famílias ribeirinhas da llha das Onças apresentam condições socioeconômicas de relevante dependência dos recursos naturais, o que ocasiona grande instabilidade nas fontes de renda e abastecimento de água para fins diários ao longo do ano. Grande parte das famílias que necessita de água para uso doméstico faz a captação de água do próprio rio, de um microssistema subterrâneo em outra ilha ou de outras fontes duvidosas nas torneiras das cidades próximas (RODRIGUES, 2016). 
Mapa 1 - Localização da comunidade do Furo Conceição

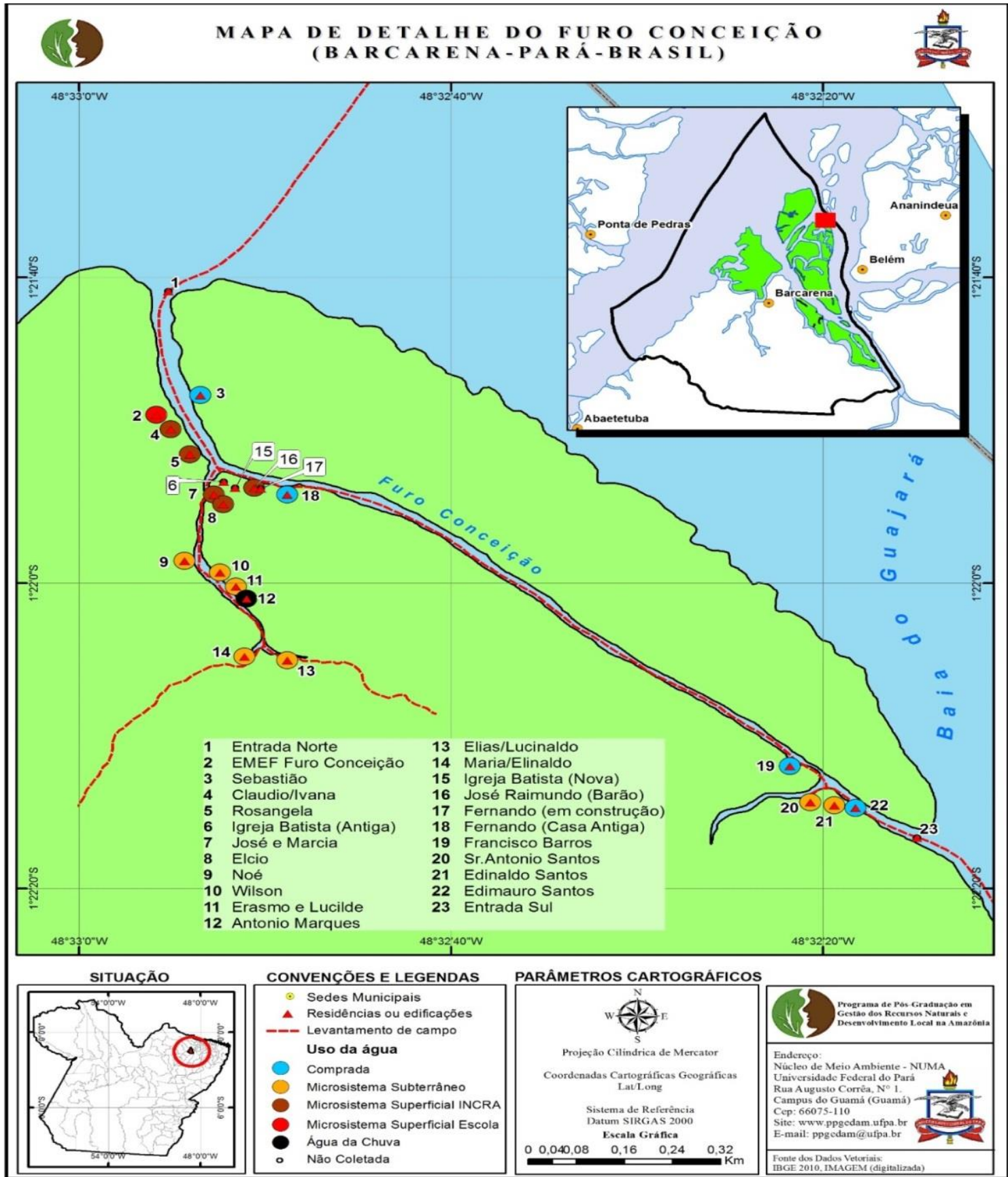

Fonte: Base Cartográfica IBGE 2010, adaptado pelo autor desta pesquisa, 2017.

\section{USOS DOMÉSTICOS DA ÁGUA NA ILHA DAS ONÇAS}

A questão do uso doméstico da água é muito presente na vida dos ribeirinhos e indispensável para sua sobrevivência. Este uso como recurso natural de grande relevância nas comunidades ribeirinhas paraenses, tem sido um meio essencial em relação à natureza, pois eles utilizam o rio para a pesca, para o lazer, transporte, higiene etc. 
$\mathrm{Na}$ segunda etapa do trabalho realizou-se, por meio de expedições a campo, com visitas frequentes e planejadas em domicílios do Furo Conceição. Para obtenção das informações sobre a importância da água para essa comunidade e sua sustentabilidade utilizou-se como base metodológica o Estudo de Caso, possibilitando ações interativas entre escola, comunidade escolar e entorno. Este método de pesquisa permite compreender a realidade em profundidade (social, econômico e ambiental) já que a pesquisa requer uma abordagem de caráter qualitativo e quantitativo descritivo com a realização de palestra educativa em parceria com a escola da comunidade e entrevistas com perguntas abertas realizadas com todos os moradores da comunidade.

Neste sentido, os moradores da Ilha relataram sobre suas insatisfações e sobre o recurso hídrico que utilizam, mencionando suas percepções sobre o uso doméstico da água que eles utilizam e o qualificando como de máqualidade. Segundo Rodrigues (2017), ocorreram mudanças de hábitos e de cultura na relação com a água do rio nas áreas ribeirinhas do Pará, pois as comunidades analisadas passaram, por exemplo, a comprar água para uso doméstico (Foto 1) em função dos problemas e impactos ambientais que estão presentes nas bacias hidrográficas de Barcarena e no leito dos rios que as circundam.

Foto 1 - a) Barqueiro entregando água de qualidade duvidosa nos domicílios; b) Água de um microssistema superficial instalado na ilha de forma ineficiente; c) Compra de água mineral na cidade mais próxima.
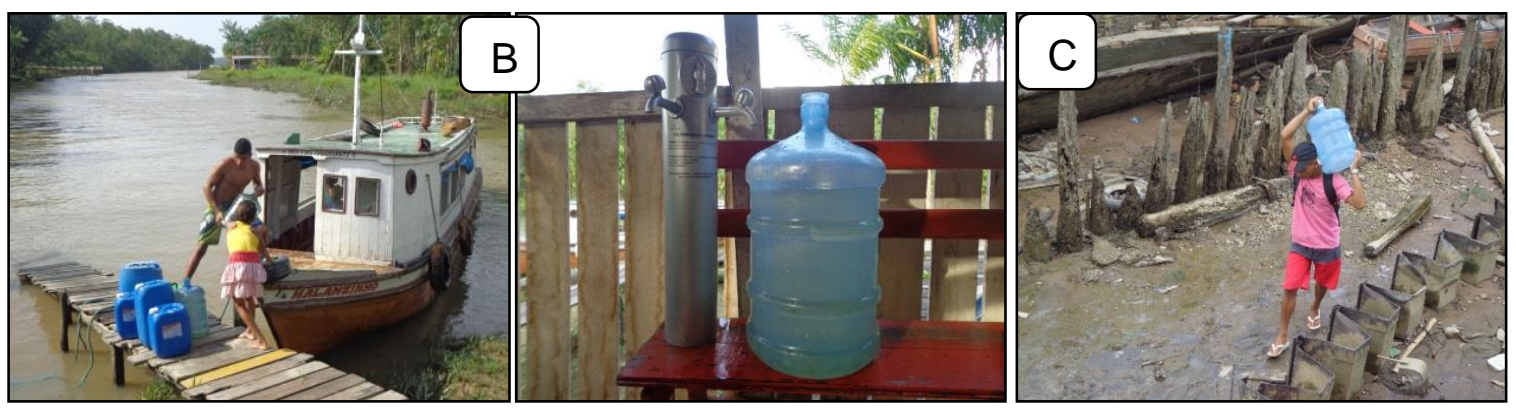

Fonte: Rodrigues, 2017.

Dessa forma, este estudo é de fundamental importância para que seja possível compreender melhor as interrelações entre os seres humanos ribeirinhos e o ambiente, suas expectativas, anseios, satisfações e insatisfações, percepções, condutas e relações com a água. Essas relações 
identificadas nos moradores do Furo Conceição podem ser e compreendidas pelos estudos etnográficos e as histórias de vida desses moradores, traduzindo nas suas vivências cotidianas e trajetórias.

\section{EDUCAÇÃO AMBIENTAL NA ESCOLA DA ILHA DAS ONÇAS}

Com o estudo e aprofundamento da temática percebeu-se que a Educação Ambiental na Ilha das Onças ainda é muito desvalorizada, não há políticas públicas consistentes sobre o tema, há falta de conhecimento da população ribeirinha sobre 0 assunto, necessitasse de capacitação dos profissionais educadores que trabalham nas escolas nas Ilhas. Nesse sentido, não existe uma elaboração de conteúdos e materiais didáticos voltados para as escolas e comunidades ribeirinhas para a sensibilização dos alunos sobre Educação Ambiental.

Por essa razão, a extensão universitária contribui para a intervenção na sociedade, ou seja, oportuniza interagir com os problemas da comunidade local. Além disso, busca desenvolver recursos didáticos e metodológicos que permitam um envolvimento da pessoa com o processo de formação docente, promovendo uma nova racionalidade quanto as suas atitudes de responsabilidade socioambiental.

A escolha do local de pesquisa e a seleção dos sujeitos participantes ocorreram devido a projetos já executados na escola Municipal Furo Conceição no seu entorno, pelo contato já estabelecido com parcerias atuantes nessa região e também pela participação dos envolvidos. $O$ trabalho se fundamenta na medida em que resulta em novas representações, difundindo conhecimentos e debates com a comunidade que irão transformar as práticas de forma significativas relacionadas aos recursos hídricos e a educação ambiental.

Construir esse processo de formação mais específico é parte das competências de educadores engajados com a causa ambiental, para que não seja somente uma questão dos temas transversais da educação a ser cumprida, mas sim um momento de aprendizado significativo.

As oficinas e palestras de sobre Educação Ambiental foram realizadas no Anexo da Escola Municipal Furo Conceição, que passou a ser o ponto de 
convergência da UFPA na área e o centro irradiador das ações de melhoria de ensino por ser um local mais apropriado em termos de espaço e acomodação das crianças e adultos que participaram das atividades. $\mathrm{Na}$ foto 2, são apresentadas as oficinas, com destaque para a questão da importância da água, dos rios e sua degradação.

Foto 2 - Palestras e oficinas de Educação Ambiental com as crianças do Furo Conceição.
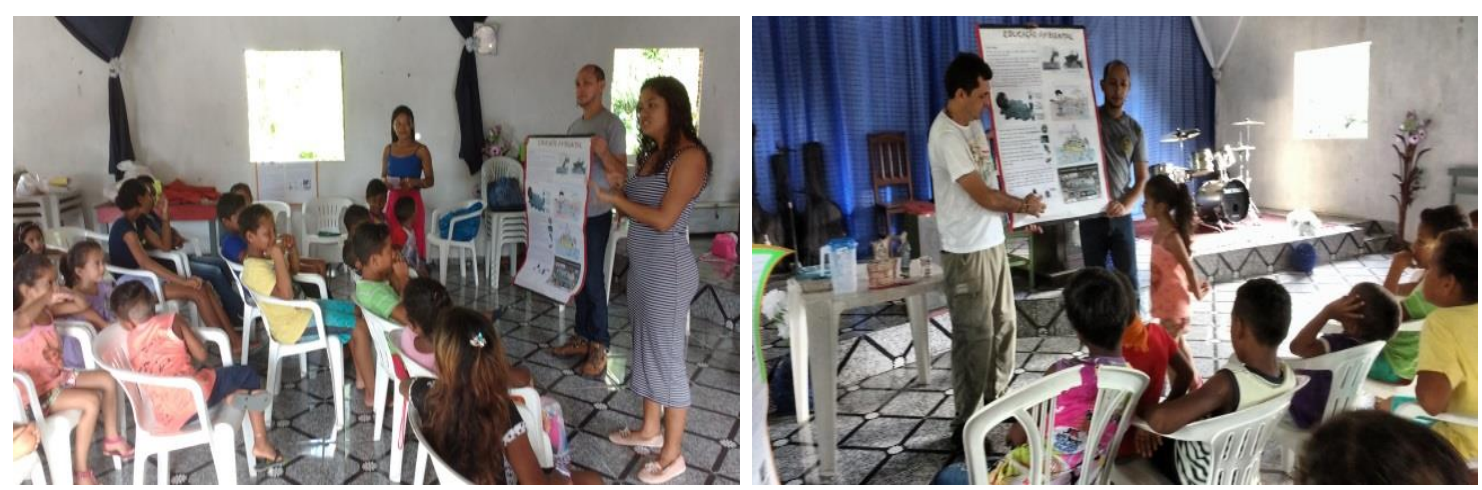

Foto: Rodrigues, 2017.

Trata-se de uma ação com abordagem interdisciplinar de Educação Ambiental envolvendo a escola local da Ilha (Escola Municipal Furo Conceição) com ênfase no processo curricular com intuito de despertá-los para uma postura de reponsabilidade socioambiental sustentável. No desenvolvimento de atividades interdisciplinares, o aluno não constrói sozinho o conhecimento, mas sim em conjunto com outros e com ajuda dos professores. É importante salientar que os professores não trabalham a interdisciplinaridade na totalidade, com os temas transversais ou projetos inovadores, cada um desenvolve seu projeto de forma isolada.

Para que a prática interdisciplinar ocorra, deve-se partir de um compromisso coletivo da escola e das metodologias de ensino. Conforme Ferreira (1999, p. 33), conceituar Interdisciplinaridade é tarefa bastante complexa, uma vez que esta palavra envolve uma acumulação diversificada de equívocos e possibilidades. Segundo Guimarães (2010, p. 32) a interdisciplinaridade é "uma forma que o professor tem para trabalhar vários temas e ou conteúdos contemplando os diferentes argumentos, mas sempre buscando ligar as disciplinas".

As atividades propostas foram desenvolvidas pelas professoras Socorro Machado e Raqueli Nascimento, professoras de Ciências Naturais, envolvendo 
a professora da ilha e alunos do Ensino Fundamental de $1^{\circ}$ ao $4^{\circ}$ ano com trabalho integrado das diferentes disciplinas ou área de estudo. Para Loureiro e Kaplan (2011), a importância de refletir sobre educação ambiental no contexto escolar é um fator imprescindível que potencializa a discussão no âmbito da educação, escola e sociedade, bem como, possibilita mudanças de atitudes e hábitos saudáveis.

O planejamento das atividades permitiu que os alunos da escola e da própria ilha (Foto 3) pudessem aplicar seus conhecimentos e pesquisas em ações educativas e aprofundar o senso de responsabilidade pelo seu próprio meio. É necessário envolver os alunos na construção do conhecimento para que sejam capazes de criticar as concepções preestabelecidas na sociedade com base em sua realidade e que refletirá em suas novas atitudes.

Foto 3 - Escola Municipal de Ensino Fundamental Furo Conceição na Ilha das Onças
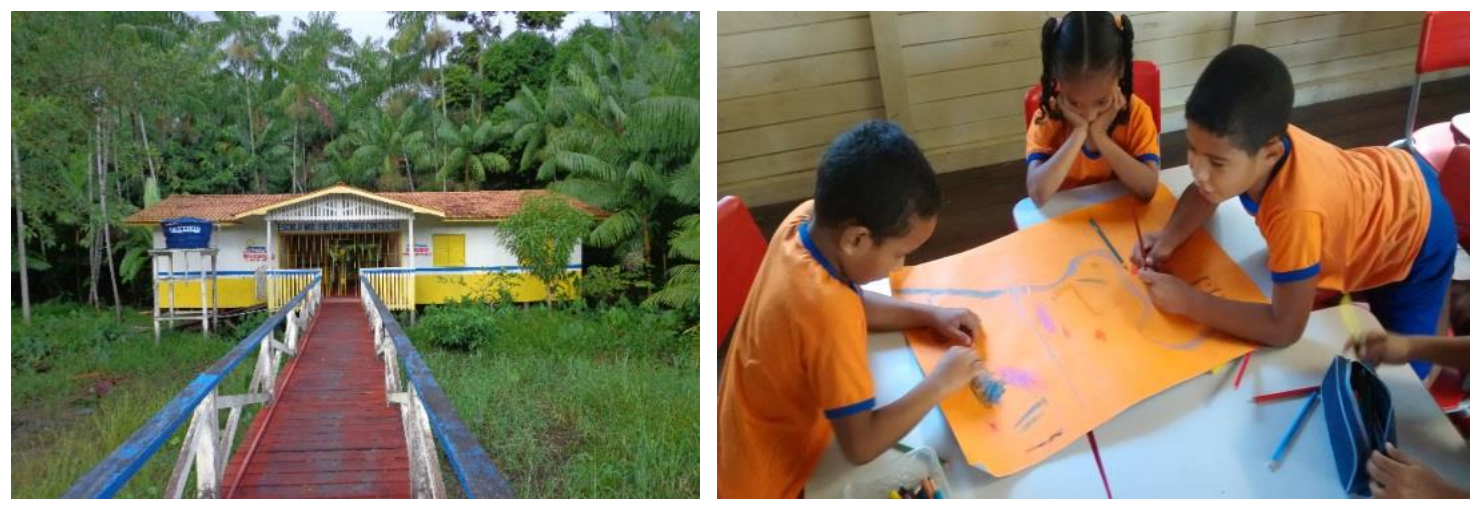

Fotos: Rodrigues, 2016.

Para que essa proposta se concretize nas escolas, é necessário o redimensionamento de planejamento de ações e do próprio currículo, pois, de certa forma, o currículo educacional ainda é concebido com princípios préestabelecidos dos conhecimentos a serem ministrados em sala de aula. Consequentemente, é através de atividades que promovam uma mudança de paradigmas em um processo contínuo de reflexão e apropriação de valores que remetem a ela, as dificuldades enfrentadas assumem características ainda mais contundentes.

A escola possui uma professora, que tem o curso de Formação em Magistério, e que atende a uma classe multisseriada de Educação Infantil do $1^{\circ}$ 
Ciclo do Ensino Fundamental (correspondente ao $1^{\circ}$, 2º $3^{\circ}$ e $4^{\circ}$ ano do Ensino Fundamental de 9 anos) no período da manhã.

No que se refere à interdisciplinaridade no currículo escolar verificou-se, na entrevista com a professora que trabalha numa classe multisseriada na referida ilha, que ela não consegue trabalhar de forma eficiente com suporte à aprendizagem de qualidade dos seus alunos. Nesse contexto, faz-se necessário definir as classes multisseriadas que, segundo Cardoso e Jacomeli (2010), são turmas nas quais um professor tem a responsabilidade exclusiva por dois ou mais níveis de escolaridade ao mesmo tempo e no mesmo espaço. Em decorrência dessa conjuntura educacional

\begin{abstract}
São muitos os fatores que evidenciam as condições existenciais inadequadas dessas escolas, que não estimulam os professores e os estudantes a nelas permanecerem ou sentirem orgulho de estudar em sua própria comunidade, fortalecendo ainda mais o estigma da escolarização empobrecida e abandonada que tem sido ofertada no meio rural e forçando as populações do campo a se deslocarem para estudar na cidade, como solução para essa problemática (HAGE, 2011, p. 99).
\end{abstract}

Cabe esclarecer que a organização do ensino no Brasil nessas regiões rurais está atrelada as especificidades locais, uma vez que é, nessa espacialidade, que essa realidade se configura. No entanto, nas sessões de palestras realizadas apresentou-se 0 conhecimento $e$ as alternativas metodológicas para a efetivação da abordagem interdisciplinar, transversal da educação ribeirinha no currículo escolar.

Compreende-se, assim, que a educação pode ser um importante suporte para a mobilização dos interesses e conflitos entre os ribeirinhos que interagem no ambiente insular, que utilizam os recursos naturais no seu cotidiano, em condições de degradação ambiental e, por fim, reivindicar o cumprimento das políticas públicas e por um sistema de abastecimento de água digno que atenda as demandas locais. Tudo isso implica garantir o acesso a vários benefícios e aos recursos naturais, a partir dos quais os ribeirinhos extrativistas sobrevivem, buscando sua autossustentabilidade

Precisa-se pensar nas transformações de todo o conjunto que envolve o processo de ensino presente em cada contexto econômico, político, social e cultural neste momento histórico, ou seja, a inserção geográfica e a identificação política, na própria realidade cultural do 
campo, tornam-se premissas fundamentais de sua implementação, ao invés de seguir uma concepção pedagógica pronta e acabada (DRUZIAN; MEURER, 2013, p.132).

Em relação à prática da Educação Ambiental nas comunidades ribeirinhas leva-se em consideração a construção de recursos pedagógicos, como palestra sobre doenças causadas pela água contaminada, jogos didáticos e atividades de pintura que veicule um saber significativo sobre a água (Foto 4).

As atividades interdisciplinares foram escolhidas por seu potencial mobilizador do público-alvo previamente definidas conforme a faixa etária dos participantes, adotando como temática central o tema transversal do meio ambiente e água, durante o desenvolvimento do conteúdo programático das oficinas.

Foto 4 - Atividades de Educação Ambiental com foco na interdisciplinaridade
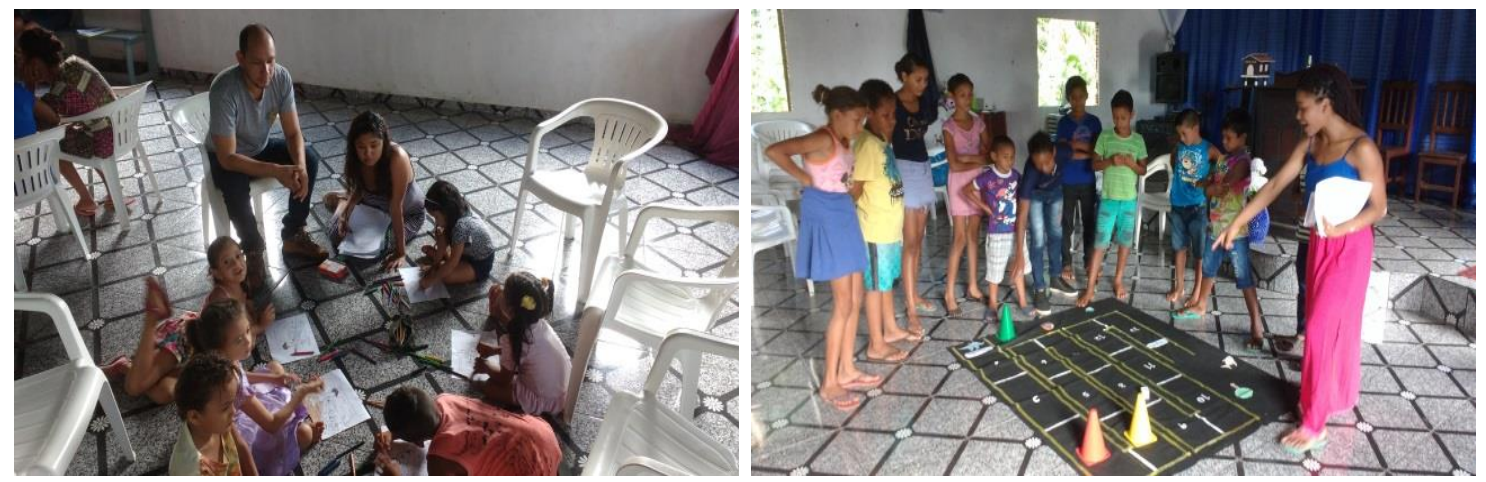

Foto: Rodrigues, 2017.

É imprescindível que no planejamento curricular seja enfatizada a preocupação com a água, recurso natural de grande importância na vida do ribeirinho, pois sua sobrevivência depende desse recurso, da forma que eles utilizam o rio para a pesca, lazer, transporte, higiene etc. Assim, o modo como a professora da llha aborda determinada temática, explicita a relação homemnatureza e o seu entendimento sobre a problemática ambiental.

Em um terceiro momento realizou-se a divisão de equipes por faixa etária e aplicou-se atividade de pintura sobre poluição, contaminação da água, além de um jogo de cartas com perguntas feitas durante a palestra, sendo estas estratégias de ensino junto com a experimentação investigativa, que 
constitui um recurso pedagógico importante para construção de conceitos científicos (Foto 4).

É importante considerar que os conteúdos de ensino sejam capazes de estimular o interesse, a curiosidade, o espírito de investigação e a capacidade de resolver problemas. No âmbito da educação ambiental implica práticas pedagógicas que viabilizem o tema meio ambiente de forma holística e contextualizada (OLIVEIRA, 2015). Assim, as crianças foram motivadas, em todas as atividades, a desenvolverem suas habilidades para que elas pudessem perceber a relação com a natureza e seus problemas locais.

Assim, existe a necessidade de investigar as diferentes formas de organização do trabalho pedagógico realizada em turmas diferenciadas por idade e aprendizagem para a reformulação da proposta metodológica dos professores e a construção de um currículo diferenciado que atenda as realidades locais.

Foi pensando nessas turmas diferenciadas de aprendizagem que se separou os alunos por idade: os de 3 aos 7 anos de idade ficaram com a atividade de pintura (Foto 4) e outro grupo de 8 a 12 anos com atividades de jogo da água. O jogo foi criado para educar, além da sensibilização e reflexão, a responsabilidade ambiental. A referida atividade foi uma pintura de observação e releitura de uma cena comum na Ilha das Onças, realizada a partir da conduta do barqueiro em jogar o lixo nos rios (Foto 5).

Foto 5 : Atividade de pintura para as crianças de classes multisseriadas de 3 a 7 anos de

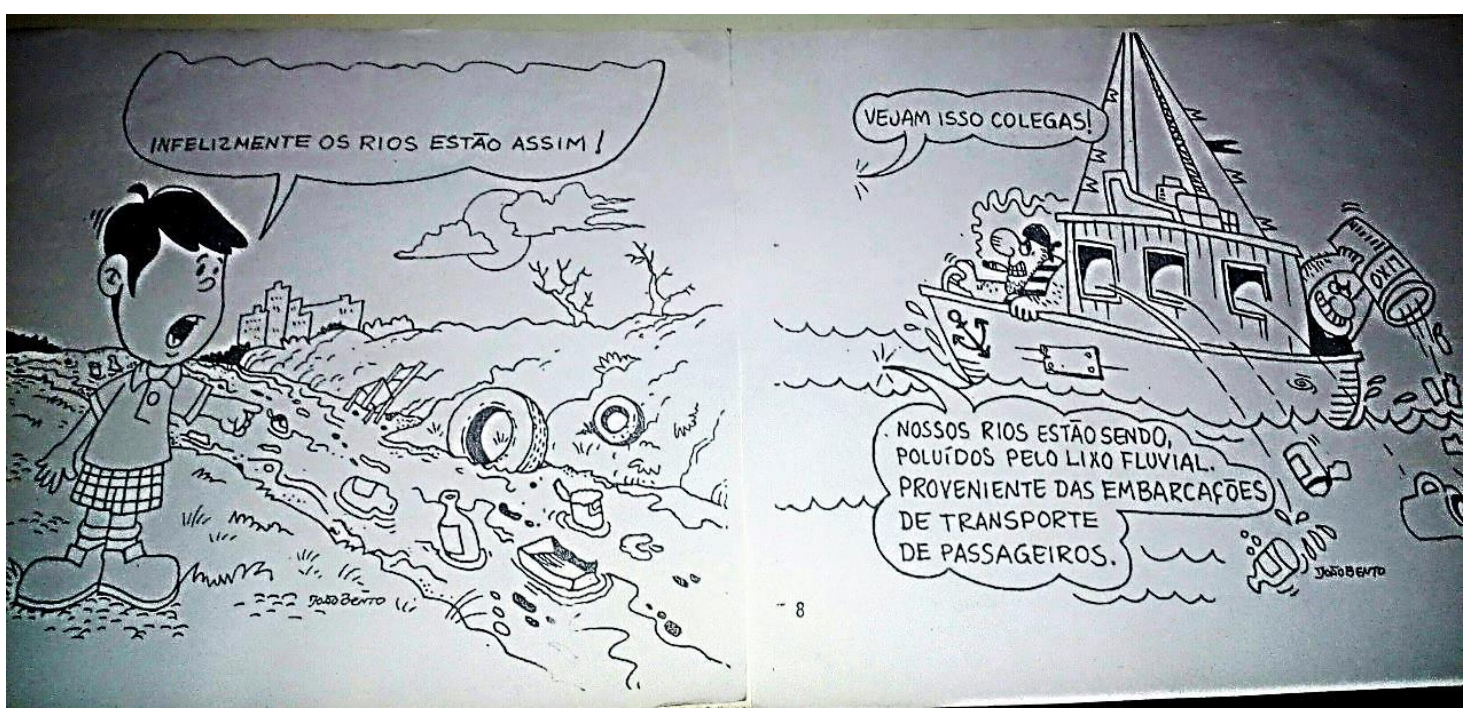

Foto: Rodrigues, 2017. 
Havia duas pinturas: uma delas mostrava dois homens em um barco, enquanto um o pilotava e o outro poluía o rio com resíduos sólidos.

No outro desenho, um menino aponta para o rio e fala que ele está cheio de resíduos. As crianças foram questionadas também sobre as consequências daquelas figuras relacionadas com o meio ambiente e água. Ao terminar a pintura, cada uma relatou qual seria sua percepção da figura.

Ao término da leitura, os colaboradores Raqueli e Rogério realizaram a interpretação oral com questionamentos que auxiliaram na compreensão e chamando atenção para detalhes importantes que poderiam ter passado despercebidos. É importante realizar discussões com as crianças a respeito da Educação Ambiental, oferecendo-Ihe suporte para realizar suas percepções e não apenas propor-lhes desenhos livres.

Um dos grandes desafios pedagógicos da Educação Ambiental para as crianças é contribuir para a formação de cidadãos responsáveis, capazes de refletir e agir sobre a sua realidade, sabendo identificar os problemas, perceber que existem soluções e, acima de tudo, que possam propor mudanças.

Dessa forma, propõe-se que a Educação Ambiental precisa estar integrada ao currículo escolar da llha das Onças sendo capaz de superar a visão fragmentada do conhecimento e que melhor qualifique o empoderamento da aprendizagem dos alunos.

\section{RESULTADOS E DISCUSSÃO}

Analisando as entrevistas feitas com os moradores da Ilha das Onças, observou-se que eles possuem certas dificuldades, como carência econômica, na área da saúde pública e do acesso à água potável de qualidade, um dos fatores em que eles são prejudicados.

As respostas às entrevistas e os depoimentos evidenciaram também que os moradores da llha possuem entendimento dos impactos das atividades predatórias sobre o seu ambiente. Acerca dessas questões, pode-se destacar uma frase de uma moradora e das crianças da escola do Furo Conceição

"Um dia desse a menina achou um negócio na água, tinha um bichinho dentro da água, eles não fazem manutenção, não limpam a casa, ai joguei o bichinho fora, tive que continuar bebendo, por que 
não tem condições para comprar todo dia a água mineral, então é assim a nossa vida é meio difícil a situação..."

Os moradores avaliaram como ações prioritárias para a comunidade o saneamento básico e a construção de um sistema alternativo de abastecimento para o consumo de água potável, visto que as águas do rio se encontram inadequadas para o consumo por causa da contaminação das águas por acúmulo de lixo e resíduos que vem prejudicando a qualidade de vida das famílias ribeirinhas.

Observando o resultado da oficina de Educação Infantil e do questionário respondido por oito crianças de 3 a 6 anos e por alguns moradores da comunidade Furo da Conceição, verificou-se que o recurso hídrico que esta população utiliza é totalmente impróprio para consumo, foi constatado que a percepção ambiental é algo que precisa ser melhor compreendido pelos moradores das ilhas.

Quanto à percepção ambiental de algumas crianças ao definir qual é água apropriada para consumo, elas têm a noção de que a interferência antrópica, às vezes, é prejudicial para o meio ambiente. Um relato de uma aluna do 5o ano bem definiu esta situação: "Quando eu tava passeando no barco do vovô eu vi um montão de água que tava verde assim ó da outra cor da cor das árvores... Todo mundo joga lixo no mar e fica fedorento".

Entretanto, outra parte das crianças (4 a 7 anos), ainda tem dificuldade de entender as atitudes inadequadas do homem com relação à degradação dos recursos hídricos que afetam à saúde. Contudo, uma prática educativa que visa à maturidade voltada às questões ecológicas, se dá através de um processo contínuo considerando a articulação e a integração dos conteúdos conceituais, procedimentais e atitudinais, tendo em vista uma nova forma de perceber as relações entre homem e natureza (OLIVEIRA, 2015).

A participação popular das comunidades ribeirinhas no entorno ao município de Barcarena se constitui num fundamento na consolidação de políticas públicas que devem ser garantidas através da criação de fóruns públicos estaduais e municipais, campanhas educativas, etc.

Entende-se que a água que os ribeirinhos utilizam não é apropriada para uso doméstico e alguns deles responderam que a única alternativa era depender de outra fonte, como o barqueiro que distribui água de qualidade 
duvidosa, apesar de saberem que não era apropriada ou então atravessar a Baía do Guajará para poder obter água mineral engarrafada, mas isso se torna dispendioso por causa dos constantes deslocamentos.

\section{CONSIDERAÇÕES FINAIS}

A comunidade ribeirinha necessita do amparo social, pois é esquecida pelo poder público, havendo esta ação continuamente, eles seriam empoderados e também instruídos de cuidar do meio ambiente, fazendo com que eles valorizem a si é a riqueza natural, constrói o autoconhecimento sobre a questão dos recursos hídricos, terão o discernimento de perceber se a água que eles estão ingerindo é própria para o seu consumo, desde as crianças até os adultos.

Este trabalho oportunizou uma reflexão sobre como a Educação Ambiental e interdisciplinaridade pode contribuir para a aprendizagem criativa das crianças ribeirinhas da Educação Infantil, observou-se que as crianças possuem muita curiosidade sobre o ambiente que as cerca, no entanto, se desinteressam facilmente pelas atividades propostas pelo professor quando estas estão descontextualizadas, é mais interessante para elas estudar um mesmo assunto por meio de diferentes metodologias, ou disciplinas, se assim preferirem.

Constata-se que ainda é necessário estratégias eficazes para avançar em políticas públicas, pois estas só serão efetivadas se houver um plano integrado de ações para as bacias, mais que isso, para toda a Região Amazônica. Tais políticas devem ser direcionadas à gestão de bacias hidrográficas inerentes às concepções presentadas com a criação de comitês e a construção democrática nos Planos Diretores Municipais para o uso dos recursos hídricos de forma responsável e autossustentável.

No entanto, a falta de vontade política municipal, ocasiona problemas na escassez ou ausência de abastecimento de água na região das ilhas paraenses, bem como a deficiência da gestão pública e falta de planejamento em todas as secretarias e níveis municipais. 
Diante dessa análise, a fragilidade da carência de políticas públicas ocasiona inúmeros problemas locais, principalmente no que diz respeito à disponibilidade de água tratada para a população ribeirinha.

Verificou-se que as escolas ribeirinhas precisam construir uma nova concepção pedagógica diferenciada para as turmas multisseriadas, que seja capaz de considerar os paradigmas, como formas diversificadas do trabalho pedagógico no âmbito das turmas por idade e níveis de aprendizagem, reformulação da proposta metodológica e curricular que atenda as especificidades dos alunos. O desafio de conceber suas ações e reflexões no âmbito do currículo com as singularidades sócio culturais e problematizando o modo de vida ribeirinho, bem como sua ressignificação.

As propostas apresentadas de Educação Ambiental interdisciplinar no decorrer deste trabalho são apenas recortes de práticas que podem ser realizadas na Educação Infantil e que permitem ao professor acrescentar novas atividades e metodologias, conforme o interesse da turma.

As concepções políticas e as matrizes curriculares devem se constituir como parte primordial de uma perspectiva pedagógica intercultural sustentável, que possibilite as bases para a construção de novas formas de sociabilidade na Amazônia e na educação ribeirinha paraense. Essa proposta de educação rural busca uma concepção de novas formas de sociabilidade, com vistas à construção de uma cultura política emancipatória de criar e recriar o contexto pedagógico concreto das populações amazônicas. 


\section{REFERÊNCIAS}

AGÊNCIA NACIONAL DE ÁGUAS (ANA). Bacias do Atlântico Nordeste Ocidental.

em:

http://www2.ana.gov.br/Paginas/portais/bacias/AtlanticoN

ordesteOcidental.aspx. Acesso em 22 de set de 2018.

BORDALO, Carlos A.; SILVA, Flávia A.; SANTOS, Viviane C. Por uma gestão dos recursos hídricos no estado do Pará: estudo de caso da bacia hidrográfica do rio Murucupi no município de Barcarena. Revista Geonorte, Edição Especial, v. 3, n. 4, p. 1216-1228, 2012.

BRASIL. Ministério da Saúde. Portaria MS n. 2.914, de 12 de dezembro de 2011. Dispõe sobre os procedimentos de controle e de vigilância sobre a qualidade da água para consumo humano e seu padrão de potabilidade. Diário Oficial [da] República Federativa do Brasil. Brasília-DF, 13 mar. 2011.

Lei 6.938, de 31 de agosto de 1981: Dispõe sobre a Política Nacional do Meio Ambiente, seus fins e mecanismos de formulação e aplicação, e dá outras providências. Diário oficial da União, Brasília-DF, 02 set. 1981.

CARDOSO, M. A.; JACOMELI, M. R. M. Considerações sobre as escolas multisseriadas: estado da arte. Educere et Educare, Cascavel, v. 5, n. 9, p. 267-290, 2010.

DIEGUES, A. C. S. Água e Cultura nas populações tradicionais brasileiras. In: COSTA, W.R. (Org.). Governança da água no Brasil: uma visão interdisciplinar. São Paulo: Annabllume; FAPESP; CNPq, 2009.

DRUZIAN, F.; MEURER, A. C. Escola do campo multisseriada: experiência docente. Geografia Ensino e Pesquisa, v. 17, n. 2, 2013.

FERREIRA, S. L. Introduzindo a noção de interdisciplinaridade. In: FAZENDA, I. C. A. (Org.). Práticas interdisciplinares na escola. 6. ed. São Paulo: Cortez, 1999.

GUIMARÃES, J. F. S. Práticas Interdisciplinares I. Aracaju: Gutemberg, 2010.

HAGE, Salomão Mufarrej. Por uma escola do campo de qualidade social: transgredindo o paradigma (multi) seriado de ensino. Em Aberto, Brasília, v. 24, n. 85, p. 97-113, abr. 2011.

LOUREIRO, C. F. B; KAPLAN, L. Análise crítica do discurso do programa nacional de formação de educadoras(es) ambientais - PROFEA: pela não desescolarização da educação ambiental. Educ. Rev. Belo Horizonte, v. 27, n. 2, p.177-196, Aug. 2011. Disponível em: http://dx.doi.org/10.1590/S010246982011000200009. Acesso em: 10 out. 2018. 
OLIVEIRA, Maria A. (Re)Pensando a formação de professores em Educação Ambiental. Revista Monografias Ambientais: Revista do Centro de Ciências Naturais e Exatas - UFSM, Edição Especial Curso de Especialização em Educação Ambiental, Santa Maria, RS, p. 08-16, 2015. Disponível em: https://periodicos.ufsm.br/remoa/article/viewFile/18732/pdf. Acesso em: 08 set. 2018.

PARÁ. Ministério Público. Inquérito Civil - IC No 001/2018-MP (SIMP N000654-710/2018. Belém: MPPA, 2018.

PESQUISA NACIONAL POR AMOSTRA DE DOMICÍLIO (PNAD). Síntese de indicadores. Rio de Janeiro: Ministério do Planejamento, Orçamento e Gestão; IBGE, 2012.

RODRIGUES, F. C. O uso doméstico da água em comunidades ribeirinhas: Diagnóstico das comunidades dos Furos Conceição e Samaúma na Ilha das Onças, Estado do Pará. 2017. 62 f. Dissertação (Mestrado em Gestão de Recursos Naturais e Desenvolvimento Local na Amazônia) - PPGEDAM/NUMA/UFPA, Belém, 2017.

SACHS, I. Ecodesarrollo: concepto, aplicación, implicaciones. Comércio Exterior, n. 30,1980.

SILVA, Regiane Paracampo da; MONTEIRO, Maurílio de Abreu. As Transformações na área Industrial de Barcarena a partir da Implantação das Empresas de Transformação Mineral. In: MATHIS, Armin; COELHO, Maria Célia; SIMONIAN, Lígia; CASTRO, Edna (Org.). Poder Local e mudanças socioambientais. Belém: NAEA/UFPA, 2007.

VIDAL, J. P.; ROSA FILHO, D. de S. Desafios de uma nova gestão pública para o desenvolvimento dos municípios no Pará. Novos cadernos NAEA. Belém, v.14, n.2, p. 171-196, dez. 2011. 